Vol. 4, Issue 4, October 2021

\title{
Building Teacher Community During a Summer of Crisis: STEAM Professional Development in 2020
}

\author{
Analía E. Rao, Jayma Koval, Sabrina Grossman, Katherine L. Boice, Meltem Alemdar, and Marion Usselman \\ Center for Education Integrating Science, Mathematics, and Computing (CEISMC), Georgia Institute of Technology, Atlanta, GA \\ Keywords: STEAM professional development, teacher training, collaboration, community building \\ Publication Date: October 4, 2021 \\ DOI: https://doi.org/10.15695/jstem/v4i4.07
}

\begin{abstract}
The GoSTEAM program promotes authentic integration of the arts into PreK-12 computer science, engineering, and invention instruction. STEM and arts teachers come together to form STEAM Innovation Teams in collaboration with university-based coaches and creative Innovators-in-Residence. Starting with a STEAM professional development summer institute and continuing throughout the year, the teams come together to design and implement novel STEAM lessons and initiatives in their schools that integrate learning goals from both the STEM and the art disciplines. This type of transdisciplinary collaboration between colleagues from vastly different fields is new to most teachers and presents unique challenges. A primary goal of the GoSTEAM professional development is therefore to create safe, interdisciplinary spaces where meaningful, cross-disciplinary collaborations can occur. In 2019, this was accomplished through an intensive, 120hour face-to-face summer professional institute that incorporated many community building activities and collaborative planning sessions. In 2020, due to the COVID-19 pandemic, the summer institute changed to an online format and faced the challenge of providing teachers with a personally meaningful STEAM experience during a summer of crisis. Results show that the 2020 institute successfully supported the teachers, energized them, and provided them with tools to augment their virtual instruction. This paper describes the program adaptations due to COVID-19.
\end{abstract}

\section{INTRODUCTION}

STEAM education, a holistic approach to education that transcends the standard boundaries between disciplinary subjects and integrates the arts to varying degrees into science, technology, engineering, and mathematics (STEM) instruction, has been promoted by many in the education community as a pedagogical strategy that equips students with the skills needed to succeed in a highly complex 21 st century workforce (Land, 2013; Quigley and Herro, 2016). According to the State Education Agency Directors of Arts Education, STEAM education is defined as "an intentional, collaborative pedagogy for teachers that empowers learners to engage in real-world experiences through the authentic alignment of standards, processes, and practices in science, technology, engineering, the arts, and mathematics" (Huser et al., 2020). In its comprehensive discussion of arts integration, the Kennedy Center also stresses that true arts integration extends beyond simply enhancing STEM lessons with arts connections that serve to help engage students (Sil- verstein and Layne, 2010). Instead, students should "construct and demonstrate understanding through an art form" and lessons should include learning objectives from both the art and STEM fields. STEAM education, at its core, should be highly transdisciplinary, not merely a way to use the arts to support other parts of the curriculum. As such, introducing STEAM integration within traditional school structures and culture requires a substantial shift in teacher focus, and a breakdown of the normal disciplinary silos that exist in schools.

As with all efforts to substantially shift classroom practice, enabling teachers to effectively teach content in such a transdisciplinary way requires a substantial and extended professional development program. Effective teacher professional development is defined by Darling-Hammond and colleagues as "structured professional learning that results in changes in teacher practices and improvements in student learning outcomes" (Darling-Hammond et al., 2017). 
These researchers identify seven characteristics of effective professional learning, namely that professional development should be content-specific and context-based, incorporate active learning, support collaboration among participants, use models of effective practice, provide coaching and expert support, offer opportunities for feedback and reflection, and is sustained over time. The interdisciplinary nature of STEAM requires additional professional development considerations. Because true STEAM education brings together educators with expertise from very disparate fields, professional learning experiences need to create interdisciplinary spaces where meaningful, cross-disciplinary collaborations can occur. Kelton and Saraniero (2018) found that having shared vision and values and taking the time to get to know each other by examining the mutual assumptions and stereotypes about each discipline were key to bringing together vastly different STEAM partners to create interdisciplinary STEAM experiences. They also found that participatory project planning and shared facilitation to ensure adequate disciplinary depth as well as balance of representation of all the fields helped to promote successful collaboration and interdisciplinary learning. Additional key components of the teachers' learning for STEAM have been found to be the fostering of collaboration and the purposeful integration of the technology (Quigley and Herro, 2017).

This paper addresses the challenge of how to create, within the online format necessitated by the COVID-19 pandemic, these interdisciplinary collaborative spaces so that teachers can successfully cross the boundaries between fields to envision and plan STEAM activities that truly integrate the arts into the technical fields of engineering and computer science.

\section{THE PROGRAM CONTEXT}

In 2018 the Georgia Institute of Technology initiated the GoSTEAM program to foster high quality PreK-12 STEAM education. The goal of GoSTEAM is to create model STEAM PreK-12 instructional materials and school initiatives that focus on Computer Science, Engineering, and Invention and Entrepreneurship, and that integrate the arts (including Fine Arts, Media Arts, Theater Arts, and Music) in authentic and compelling ways that promote positive STEAM identity. The program includes a substantial evaluation component to assess the effects of the programs on student outcomes such as student engagement, academic self-efficacy, and 21 st Century Skills such as problem-solving, teamwork, and collaboration. Researchers are also studying teacher impacts such as teaching self-efficacy, the development of teacher social networks, and teacher collaboration.

Each GoSTEAM school has a STEAM Innovation Team, consisting of STEM and arts teachers partnered with a creative Innovator-in-Residence ("Innovator") and a support coach from Georgia Tech. Innovators are members of the community who are employed for 20 hours per week in residence at the school. They are often associated with the Makers movement or educational programs such as Georgia Tech's Music Technology program or local Design schools. The support Coaches are experienced educators who have worked extensively with teachers in professional learning settings and who have substantial experience in developing STEAM curricula. GoSTEAM supports nine schools per year, ranging from elementary to high school. The Innovation Team at each school is tasked with designing and implementing STEAM-integrated learning experiences in their school, working with the evaluation team to assess impacts, and documenting the instructional materials.

The GoSTEAM program begins with a summer institute held at Georgia Tech, where Innovation Teams become familiar with a common set of pedagogical strategies and disciplinary content, and members collaborate to create school-level Action Plans for the upcoming year. The Action Plan includes the details of the planned integrated STEAM lessons and initiatives and spells out the role of each individual on the team, the student learning goals for both STEM and the arts, goals for educators and the school community, and the nature and scope of the integration. The Action Plan also includes implementation details, highlights any additional resources that are required for implementation, and proposes an assessment plan to determine the level of success along multiple axes.

The teachers from each school come from very different fields and, though they are colleagues, have generally not collaborated previously on curricular materials or on instruction. For instance, the engineering teacher and dance teacher at one high school formed the nucleus for a STEAM Innovation Team, the computer science teacher and band director at another, and a middle school tapped a 6th grade science teacher and the chorus teacher. Six of the nine schools from Year 1 returned for Year 2 in the program, with the requirement that they expand their Innovation Team to include additional STEM and/or arts teachers. Three schools in Year 2 were completely new. GoSTEAM was preparing for a second face-to-face summer institute when COVID-19 forced a complete change in plans. This manuscript will describe the adaptations we implemented to create a virtual summer professional development institute that used STEAM experiences and technological tools to build community and provide teachers with a meaningful experience during a summer of crisis.

\section{TEACHERS' STEAM PROFESSIONAL DEVEL- OPMENT: THE PRE-COVID-19 EXPERIENCE}

The first teacher professional development institute was held in the summer of 2019. The initial cohort consisted of 
18 teachers from the nine participating schools, representing three different school districts. Teachers in the technical fields included science, mathematics, engineering and mechatronics, computer science, and social studies. Art teachers included the fields of music, chorus, dance and theater, visual arts, drama, and fine arts. Additional participants included seven of the nine Innovators-in-Residence and the support coaches from Georgia Tech.

This 120-hour summer institute was facilitated by the GoSTEAM program team and included one week of online self-paced instruction on Project-Based Learning followed by four weeks of face-to-face collaborative workshops, STEAM-focused field trips, and planning sessions. For this immersive experience, participants met with program staff Monday through Friday for three weeks in June for approximately six hours per day on the Georgia Tech campus. During one additional week, participants met together at their school sites to collaboratively analyze the strengths, weaknesses, opportunities, and threats for their school (a SWOT analysis) and to work on their Action Plans. Seventeen of the 18 initial teachers completed the program and were paid a stipend of $\$ 2,500$. Evaluation results, described in detail elsewhere (Boice et al., 2021), documented that the summer institute supported teacher implementation of STEAM, and positively impacted teachers' collaboration, pedagogy, self-efficacy, and arts integration practices.

The goals of the summer institute were to:

1. Build collaborative teams

2. Model strong project-based, student-centered pedagogy

3. Introduce the foundations of STEAM pedagogy

4. Increase cross-disciplinary content knowledge

5. Develop interdisciplinary instructional materials

6. Plan for school year implementation of a STEAM Action Plan

The professional development was a mixture of whole group instruction, pathway-specific meetings, and Innovation Team collaborations. Most workshop time slots could be classified into one of six categories: Pedagogical instruction, technical content enhancement, arts content enhancement, integrated STEAM experiences, community building, and collaborative planning. These categories sometimes overlapped, as face-to-face instruction modeled using student-centered pedagogy also, by its nature, promotes community building. During face-to-face instruction in Year 1, some hours were also taken up with extraneous activities such as filling out forms and traveling to field trips. These activities were classified as "Other." Table 1 shows a sampling of the professional development activities from Years 1 and 2.
Table 1. Sample activities from Years 1 and 2 professional development offerings.

\begin{tabular}{|c|c|c|}
\hline Content & Year 1 & Year 2 \\
\hline \multirow{3}{*}{$\begin{array}{l}\text { Pedagogical } \\
\text { Instruction }\end{array}$} & $\begin{array}{l}\text { Project-Based Learning and } \\
\text { STEAM foundations (VA) }\end{array}$ & $\begin{array}{l}\text { Project-Based Learning and } \\
\text { STEAM foundations (VA) }\end{array}$ \\
\hline & $\begin{array}{l}\text { Design Thinking (S), } \\
\text { Assessment (S) }\end{array}$ & Assessment (VS) \\
\hline & $\begin{array}{l}\text { Voice and Choice, Culturally } \\
\text { Responsive Pedagogy, } \\
\text { Culturally Authentic } \\
\text { Practices* (S) }\end{array}$ & $\begin{array}{l}\text { Voice and Choice, Culturally } \\
\text { Responsive Pedagogy* (VS) }\end{array}$ \\
\hline \multirow{4}{*}{$\begin{array}{l}\text { Community } \\
\text { Building }\end{array}$} & Group PBL Activity (S) & $\begin{array}{l}\text { Morning Prompts and Music } \\
\text { (VS) }\end{array}$ \\
\hline & $\begin{array}{l}\text { Art Scavenger Hunt on } \\
\text { Campus (S) }\end{array}$ & $\begin{array}{l}\text { Open Virtual Office Hours } \\
\text { (VS) }\end{array}$ \\
\hline & Fishbowl Discussions (S) & $\begin{array}{l}\text { Musical Instrument Challenge } \\
\text { (VS and VA) }\end{array}$ \\
\hline & Posting of individual bio (VA) & Posting of individual bio (VA) \\
\hline \multirow{3}{*}{$\begin{array}{l}\text { Collaborative } \\
\text { Planning }\end{array}$} & SWOT Analysis (S) & SWOT Analysis (VS) \\
\hline & Action Plan Work (S) & Action Plan Work (VS and VA) \\
\hline & Visits to schools (S) & $\begin{array}{l}\text { Work sessions with coaches } \\
\text { (VS) }\end{array}$ \\
\hline \multirow{3}{*}{$\begin{array}{l}\text { Technical } \\
\text { Content } \\
\text { Enhancement }\end{array}$} & $\begin{array}{l}\text { Computer coding with } \\
\text { EarSketch (S) }\end{array}$ & Coding with EarSketch (VS) \\
\hline & $\begin{array}{l}\text { Swarm Robotics/Visit to the } \\
\text { Robotarium (S) }\end{array}$ & Circuit Board Activity (VS) \\
\hline & $\begin{array}{l}\text { Arduinos Hands-on Session } \\
\text { (S) }\end{array}$ & $\begin{array}{l}\text { Using Arduinos to Make a } \\
\text { Paper Piano (VS) }\end{array}$ \\
\hline \multirow{3}{*}{$\begin{array}{l}\text { Arts Content } \\
\text { Enhancement }\end{array}$} & Museum of Art Visit (S) & $\begin{array}{l}\text { Panel with Coordinator from } \\
\text { Museum of Art (VS) }\end{array}$ \\
\hline & $\begin{array}{l}\text { Center for Puppetry Arts Visit } \\
\text { (S) }\end{array}$ & $\begin{array}{l}\text { Panel with Coordinator from } \\
\text { Center for Puppetry Arts (VS) }\end{array}$ \\
\hline & $\begin{array}{l}\text { Music Composition Lecture } \\
\text { (S) }\end{array}$ & Dance and Drama (VS) \\
\hline \multirow{3}{*}{$\begin{array}{l}\text { Integrated } \\
\text { STEAM } \\
\text { Experiences }\end{array}$} & Prototyping Puppets (S) & Advanced Puppetry (VS) \\
\hline & $\begin{array}{l}\text { Jello Piano - Hands-on } \\
\text { Activity }(\mathrm{S})\end{array}$ & Cake Engineering (VS) \\
\hline & Paper Mechatronics (S) & Paper Piano - Arduinos (VS) \\
\hline
\end{tabular}

Face-to-face Synchronous (S), Virtual-Synchronous (VS), Virtual-Asynchronous (VA). *This content was also considered to be Community Building.

As depicted in Table 1, the Year 1 activities related to Pedagogical Instruction introduced participants to best practices in STEAM pedagogy and included deeper dives into Project-Based Learning, Design Thinking, and Culturally Responsive Pedagogy. Teachers and Innovators also completed a 5-hour online Project-Based Learning (PBL) course before they attended the summer institute. The course was designed to provide a foundation to support their summer work, and included introductory readings, videos, and online discussions about PBL and STEAM best practices. It was the first place where the teachers were introduced to the other members of their cohort and team.

The Community Building activities provided opportunities for the entire group to build rapport and share ideas, experiences, and stories with each other. These experiences included daily reflections, a 'Hidden Arts' scavenger hunt on campus, and a fishbowl activity, as well as sessions that focused on culturally responsive pedagogy and how to weave 
in social justice through the arts. These latter workshops were included in both the Pedagogical Instruction and Community Building categories in Table 1.

Activities in the Technical Content and Arts Content enhancement categories were opportunities for all participants to increase their cross-disciplinary content knowledge. The Technical Content sessions included workshops on computer coding with EarSketch (a platform that helps students learn core topics in computer science, music, and music technology), robotics, and tours of technology-focused campus resources and labs. The Arts Content sessions leveraged the rich local arts opportunities, as participants toured the local Museum of Art and the Center for Puppetry Arts, and experienced graphic and arts-focused data visualizations at the Centers for Disease Control and Prevention.

Integrated STEAM Experiences combined both technical and arts content to create innovative products and were important for helping Innovation Teams envision what STEAM integration could look like in their classrooms. Sessions included Prototyping Puppets, which combined craft and performance art; Jello Piano, in which participants created pianos using Arduino micro-controllers; and Paper Mechatronics, where participants learned techniques for combining mechanical movements with paper crafting.

The Collaborative Planning activities took up the majority of the summer institute hours and consisted of work sessions where Innovation Teams brainstormed and developed their school-level Action Plans and SWOT (Strengths, Weaknesses, Opportunities, and Threats) analyses. The teams' SWOT analyses focused on the teachers' school and community contexts and were used to determine what factors would give them greater success with implementing their Action Plans and to anticipate any challenges that could affect implementation. Innovation teams also explored how they could incorporate STEAM, technical and arts content from summer workshops into their Action Plans.

The summer institute culminated with a final celebration where the entire GoSTEAM cohort gathered together with invited school leaders and project partners. Innovation Teams presented their STEAM Action Plans for the school year and the audience had the opportunity to comment and offer resources and advice regarding the plans.

\section{TEACHERS' STEAM PROFESSIONAL DEVELOPMENT: PROGRAM ADAPTATIONS DUE TO COVID-19}

During the fall of 2019, the nine Innovations Teams began implementing their first STEAM Action Plans. In March 2020, the COVID-19 pandemic forced all teams to pivot to virtual instruction, and the program staff had to completely reassess the upcoming summer professional development institute to adapt to the new reality. How could the sum- mer institute be adapted to a virtual environment while still maintaining the desired levels of engagement and effectiveness? How could the teachers, Innovators, coaches, and staff build a collaborative community in this new virtual environment, without the in-person, highly immersive experience that was so impactful during the first summer? How could GoSTEAM assist teachers in preparing for a fall semester of virtual instruction? And, as the spring and summer erupted with racial justice protests, how could the GoSTEAM summer institute provide teachers with a personally meaningful experience that enabled them to express their thoughts and emotions through STEAM during a summer of crisis? It was clear that we had to be very intentional in our efforts to build a collaborative community among teacher participants, many of whom were meeting for the first time in this virtual platform, and all of whom were under a great amount of stress. The goals of the 2020 summer institute were therefore modified to focus primarily on two objectives:

- To build fulfilling collaborative communities that supported teachers and empowered them to express their voices through STEAM experiences; and

- To model the use of technological tools that might augment their own upcoming virtual instruction.

\section{SUMMER PROFESSIONAL DEVELOPMENT ADAPTATIONS DUE TO COVID-19}

Program Delivery Format and Length. Due to the COVID-19 pandemic, the 2020 GoSTEAM summer professional development institute was hosted entirely online, using the Canvas learning management system, and the BlueJeans digital platform. New teachers were required to first complete the 5-hour introductory asynchronous online STEAM PBL course to provide the common foundation. The institute then met synchronously as a whole group for two 1-hour sessions daily during three weeks in June, and participants worked for, on average, an additional two hours per day on either asynchronous work or on collaborative, virtual work with team members. A total of 26 teachers, 12 of whom were returning for their second year of participation in the program, received credit for 60 hours of professional development, and received a stipend of $\$ 1,000$. Support Coaches also participated in the institute. Before the summer institute began, participants were provided with a kit of materials that allowed them to engage in hands-on STEAM activities offered throughout the summer institute.

Program Content and Focus. The Year 2 professional development activities, all of which were modified for virtual delivery, are listed in Table 1. Similar to Year 1, the Pedagogical Instruction activities focused on topics related to STEAM content and pedagogy, such as assessment strate- 
gies, culturally responsive and social justice pedagogy, and best practices to promote student voice and choice. Invited speakers for these sessions included university faculty and practitioners, some of whom were from out of state.

To increase participants' cross-disciplinary content knowledge, the summer institute offered online sessions for both the Technical Content and Arts Content enhancement. The Technical Content sessions were hands-on in nature and included coding with EarSketch, circuit boards, and the use of Arduinos to make a paper piano. Due to the inability to conduct site visits, the Arts Content enhancement activities had to be completely redesigned to offer meaningful experiences. This was accomplished by providing a panel with guest speakers from local arts organizations, and a dance and drama workshop led by a returning GoSTEAM dance and drama teacher.

The Collaborative Planning times, when teachers, support coaches, and Innovators met online to develop and refine their STEAM Action Plans, were scheduled by the individuals to accommodate challenging home schedules and personal preferences. We created numerous virtual rooms that were always available within our digital platform to facilitate and promote collaboration among Innovation Team members. The amount of time devoted to collaborative planning was decreased substantially in Year 2, as shown in Figure 1, both because of the risk of teacher online burnout, and because teachers found it challenging to develop STEAM Action Plans in the midst of extremely uncertain times imposed by the pandemic. Teachers did not know whether they would return to school face-to-face or virtual in the fall semester, therefore it was difficult to determine a STEAM Action Plan for the unknown.

Confronted with the challenges of building a collaborative community in the virtual environment, Community Building activities were planned very purposefully and were a larger focus for the professional development program compared to Year 1. By its nature, the virtual environment decreases the opportunities for teachers to engage in the type of informal interactions that organically occur during a faceto-face program. In addition to interacting during planned community building activities, teachers in Year 1 stayed for discussions after workshops and presentations, gathered together during lunch and breaks, and conversed during field trips. None of these informal interactions were possible in the online space, so alternate activities needed to be implemented.

The Community Building activities in Year 2 included daily welcome prompts that participants were asked to answer each morning as they joined the virtual space. The prompts consisted of emotional check-ins, reflections on their unique strengths, positive coping skills, and gratitude prompts. Teachers were asked to type their answers in the shared chat box. These prompts intentionally focused on

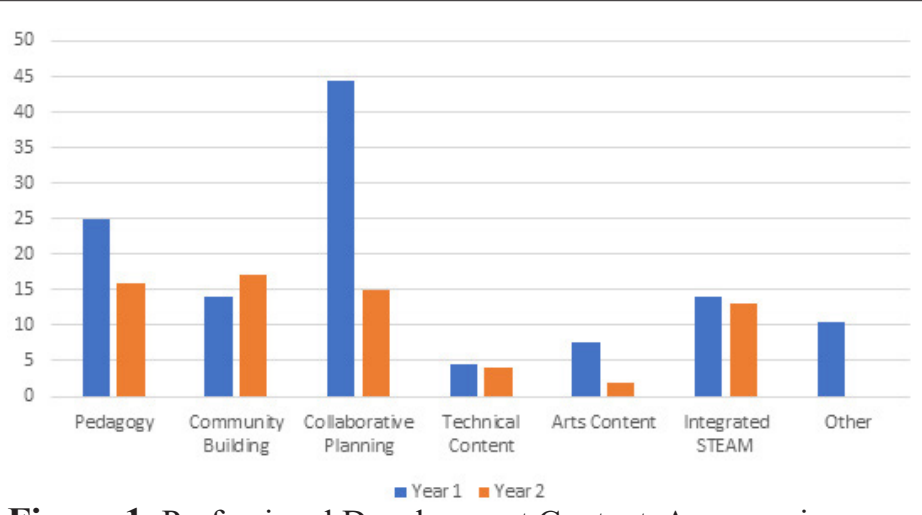

Figure 1. Professional Development Content. A comparison between the number of hours of content offered in Years 1 and Year 2.

teachers' emotional well-being during a very stressful time, and promoted engagement, connectedness, and the building of a supportive community. This daily exercise was accompanied by music selected and played in the background by a rotating group of teachers who were willing to share their preferred songs. However, the primary community building activity was an institute-long collaborative Musical Instrument Challenge, designed to promote a rewarding collaborative community that supported teachers and empowered them to express their voices through a STEAM experience. The challenge also served to further the second goal of the summer institute, namely, to introduce teachers to the types of technological tools that might enhance their own upcoming virtual instruction.

The Musical Instrument Challenge. This project was inspired by the Guthman Musical Instrument Competition, one of the nation's premiere events for music technologists, and also by Zoom performances that were being broadcast during the spring of 2020 by artists such as the cast of the musical Hamilton. The project challenged teams of teachers to collaboratively design new musical instruments, add creativity and digital technology, and deliver a 5-minute, pre-recorded video performance at the end of the summer institute. The performance could include vocals, dance, special effects, photography, or any other creative effort. The project teams were instructed to upload their final project onto a shared web platform. Teachers had three weeks to complete the challenge and all collaborations had to be scheduled by the team and done remotely. The directions for this assignment were intentionally broad, as we wanted to promote teachers' voice and choice as well as innovation and creativity.

Because this project was designed not only as a concrete example of a STEAM challenge, but also as a way of fostering transdisciplinary communities in the virtual environment, teachers were intentionally grouped into six teams of 5-6 people, with representation across school systems, schools, disciplines, and skillsets. 
There were six finished projects and they varied in content, instrument selection and how the group members collaborated. Most projects incorporated participants' voices, whether through narration or singing. Some group members created instruments using materials that were readily available, such as maracas (plastic bottles with beads), harmonicas (straws, popsicle sticks, and rubber bands), drums (pots, pans, and sticks) and flutes and percussion pipes made with PVC pipes, while other teachers created electronic instruments from equipment they had received from the program. One MIDI Arduino instrument combined an oatmeal container, a Bare conductive board, alligator clips, brass brads, and a speaker and batteries. Teachers also shared their digital technology talents with their groups by incorporating technologies and media platforms such as EarSketch, SoundTrap and TikTok.

The open nature of the challenge allowed participants to express their own thoughts and emotions about the issues of justice and equity in ways that were very personal and cathartic. One group created an emotionally powerful video where each team member elevated the voice of a different group of students who are often overlooked by their educators. The five-minute video utilized narrative, music, and stock images of students, highlighting students with learning disabilities, immigrant students, multilingual learners, and students who might struggle in school because of competing demands between academics and family obligations. The video combined powerful music and sounds with narrations of students telling their teachers about their unique realities and school experiences. It included language reflective of the events of summer 2020, including references to "I can't breathe."

Another group found inspiration for their project from their daily professional development experiences, as they wrote a song with a catchy tune and lyrics and created a project centered on their need for morning coffee. This video featured all group members and incorporated song, dance, graphics and filters and special effects that are used in popular TikTok videos. Instruments included saxophone, guitar, and drums that were made of pots and pans.

While some groups created projects that were a collaborative effort in which each participant lent their talents to a combined effort, other groups took an approach where each member created their own project, highlighting their own perspective, but using the same video format. In one example, group members each created their own instrument out of materials they had readily available and made a video in which they performed the instrument. This included a 'Hose pipe horn', which the teacher created using a garden hose, brass mouthpiece, and a funnel and used to perform a song in celebration of New Orleans. Another participant built a guitar using a cardboard box, brads and rubber bands. In her video, she acknowledged that the instrument did not turn out as well as she had hoped and opted instead to narrate a poem she had written without musical accompaniment. Her poem reflected her experiences as a woman of color during the emotionally turbulent summer.

The musical instrument challenge prompted high levels of interactions to occur outside the formal professional development time, as the cross-disciplinary and cross-gradelevel teams worked together to complete their projects. The challenge enabled teachers to interact in a safe, cross-disciplinary space where everyone's unique skills and strengths were valued. The summer institute culminated with a showcase of the innovative products teachers created for the $\mathrm{Mu}$ sical Instrument Challenge.

\section{EVALUATION METHODS}

On the final day of the 2020 summer professional development institute, all teachers were invited to participate in a post-survey designed to investigate teachers' perceptions of and satisfaction with the virtual professional development experience. The online survey contained both Likert scale and open-ended items. In addition to assessing satisfaction with each professional development session, the survey included items to assess teachers' overall experience during the institute, the perceived impact of the professional development, their understanding of STEAM integration, the Musical Instrument Challenge, and opportunities to collaborate during the summer institute. Teachers were also asked to share suggestions they had for improving the professional development. In this paper, we focus on the findings related to institute activities designed to foster Community Building and Collaborative Planning and teachers' perceptions of their overall experience in the summer institute.

Participants. Of the 26 teachers who participated in the virtual summer institute, 18 completed the post-survey. Approximately half of the participants were returning teachers in their second year of the program (44\%) and half were in their first year in the program (56\%). The participants reflected the larger group of GoSTEAM teachers in that approximately one-third of participants reported teaching elementary school (39\%), one-third reported teaching middle school (33\%), and one-third reported teaching high-school $(28 \%)$.

\section{RESULTS: PROFESSIONAL DEVELOPMENT PROGRAM IMPACT}

Perceptions of Overall Experience. Conducting the 2020 summer professional institute online, while challenging for some, was a positive, successful experience for most participants. All participants reported that their overall experience in the institute workshops was "good" $(25 \%)$ or "very 
good" (75\%), with participants describing their experience attending the professional development online as "informative and enjoyable," "very educational," "a unique way of connecting," and "engaging." Opportunities to gain exposure to technology and ideas which could be implemented in their classrooms, as well as opportunities to collaborate, contributed to teachers' positive perceptions of the experience. When asked which aspects of the summer institute were most helpful, participants frequently described specific workshops during the summer institute which were most helpful. Some participants indicated that opportunities to collaborate during the institute were most helpful to them. Additionally, the virtual format of the institute was helpful for some as they prepared for potential online instruction in the coming school year. When asked to share suggestions for improving the summer institute, some participants requested additional support with specific STEAM content and with collaboration, while anticipating that the Innovators would take on these roles during the school year by contributing ideas and actively collaborating with teachers. Participants suggested that the summer institute could be improved by extending the length of the workshop sessions and slowing down the pace of the sessions so teachers could better grasp the information. These suggestions indicate that participants had a positive experience overall, with participants emphasizing both content and collaboration, and requesting additional time devoted to both of these aspects of the summer institute.

Perceptions of Community Building. The post-survey also assessed teachers' perceptions of one of the primary Community Building activities during the summer institute, the Musical Instrument Challenge. Teachers rated their agreement with items assessing their experiences completing the Musical Instrument Challenge on a 5-point scale, ranging from "strongly disagree" (1) to "strongly agree" (5). Participants agreed with all statements, on average, indicating their overall satisfaction with the Musical Instrument Challenge (Table 2).

Participants were asked to share additional feedback about the Musical Instrument Challenge in an open-ended item. The majority of the respondents described the challenge as a positive experience. For example, one participant

Table 2. Satisfaction with Musical Instrument Challenge.

\begin{tabular}{ll}
\hline & M (SD) \\
\hline $\begin{array}{l}\text { I enjoyed working on the Challenge. } \\
\text { I was able to successfully collaborate with my Challenge team }\end{array}$ & $4.47(0.62)$ \\
online. & $4.41(0.51)$ \\
I had enough time to work with my team on the Challenge. & $4.29(0.77)$ \\
$\begin{array}{l}\text { The Challenge help prepare me to implement STEAM activities } \\
\text { in my own school. }\end{array}$ & $4.18(0.88)$ \\
\hline $\begin{array}{l}\text { Note. } n=17 . \text { Participants rated their agreement on a 5-point scale, ranging from } \\
\text { "strongly disagree" (1) to "strongly agree" (5). }\end{array}$
\end{tabular}

Journal of STEM Outreach

7

stated, "I really got absorbed in a positive way in the making and tweaking of my musical instrument! It was a great way to feel like a student again and experience what our students experience." Another participant highlighted how this challenge fostered a sense of community, stating that the Musical Instrument Challenge was "very fun and a great way to get to know other people who are part of GO STEAM."

Perceptions of Collaborative Planning. As described above, participants described collaboration as a positive and helpful aspect of the 2020 institute experience when asked about their overall experiences in the summer institute. In addition, participants were specifically asked about collaborative planning activities in the institute, including working on their Action Plan and work sessions with their Coaches and Innovators. When asked to describe the ways in which the summer institute prepared them to design their Action Plans, participants reported that the experience provided them with new and creative ideas, as well as opportunities to collaboratively plan. For example, one participant described the benefits of collaborative planning on the Action Plan as they prepared for the unique challenges of the coming school year, stating, "there are so many unknowns going into this school year, but I felt that collaborating with other teachers helped me to anticipate some of the craziness that this year might bring." Participants reported that the working sessions with their Support Coach were "useful," allowing them to "ask questions and get clarity" and preparing them to "work together for the rest of the year." Though one participant reported that "appropriate time was given," the majority of respondents wanted more time to collaborate with their Coach and/or Innovator during the summer institute. One participant remarked on the constraints of collaborating with their Coach in a virtual environment compared to collaborating in-person during the previous year's professional development, stating, "it was helpful but challenging to do online. Last year we had a lot of conversations when we were at lunch or on break. We just didn't get the same time together this summer because of COVID." These responses suggest that Collaborative Planning activities were indeed useful for supporting teachers' collaboration during the summer institute, despite the challenges of collaboration in a virtual environment. Furthermore, the collaboration opportunities during the summer institute were mentioned by participants throughout the survey as they reflected on the useful and positive components of the virtual professional development.

\section{GOSTEAM SCHOOL-YEAR IMPLEMENTA- TION AND COVID-19 ADAPTATIONS}

Each STEAM Innovation Team is normally expected to implement their Action Plan during the school year and to 
work with the GoSTEAM evaluation team to assess student impacts. Teachers receive $\$ 500$ stipends each semester for 1) actively participating with their teacher colleagues, Innovator and coach; 2) updating and implementing their Action Plan; and 3) providing reflection feedback to the GoSTEAM management and evaluation team. During Year 1, this process went as planned until March 2020, at which point teachers pivoted into a survival mode and for the remainder of the semester the GoSTEAM staff attempted to merely support them in whatever ways possible. To receive their spring 2020 stipend, teachers only needed to stay engaged with the program and provide an end-of-year reflection. Data collection related to student outcomes was also suspended and not resumed during the 2020-2021 schoolyear per school system decree.

Because of COVID-19, 2020-2021 (Year 2) schoolyear activities and program engagement requirements were adjusted to take into account the uncertainties and implementation challenges teachers would face as they returned to their schools in the fall. All schools began the fall semester in a completely remote format, but different school systems implemented different schedules during the year, ranging from all remote to various hybrid formats. Anticipating these challenges, the GoSTEAM program staff decided to not require implementation of Action Plans if the situation in the school precluded it. Instead, revised requirements were set for the schoolyear to maintain teacher engagement with the program under the special circumstances. To receive their fall 2020 stipend, teachers were required to submit 1) an updated STEAM Action Plan; 2) an updated SWOT Analysis that incorporated further understandings of the school context during the pandemic and factors that impacted implementation of the Action Plan; and 3) a reflection post on a shared platform. As part of this reflection activity, teachers were asked to reflect on their own learning experiences as they attempted to implement their Action Plan and to give and receive feedback from their GoSTEAM peers. To receive their spring stipend, teachers were again asked to submit a discussion post, reflecting on the many challenges faced with implementation during the COVID-19 year as well as lessons learned and plans moving forward.

One success measure of teacher engagement and the strength of the collaborative community is the retention of teachers in the program. Of the 26 teachers who participated in the summer 2020 professional development, 23 of them completed all requirements during the school year, and 18 continued with GoSTEAM for 2021-2022 (Year 3), starting with the summer 2021 professional development institute. Of the eight teachers who did not continue, six did so because they transferred to different schools that were not part of the program. Only two left GoSTEAM but stayed at their existing schools, citing the pressures of COVID-19 and the need to rebuild programs decimated by the pandemic. The
18 teachers who returned for Year 3 recruited 24 additional teachers from their schools, creating a vibrant and engaged cohort of 42 teachers.

\section{CONCLUSIONS}

The 2020 global pandemic presented unprecedented challenges to the implementation of the teachers' STEAM professional development institute. The immersive experience had to be transformed to a virtual setting in the midst of a summer of crisis. This included adaptations to the program delivery format, going from an intense and highly interactive experience to an entirely virtual experience, and changing the program length from a 5-week (120 hours) experience to a 3-week (60 hours) one. All the content activities had to be modified for a virtual delivery. Additionally, yearlong activities and program requirements had to be modified due to the challenges that participants faced with Action Plan implementation during the pandemic year.

We addressed the challenges of how to create, within the online format necessitated by the COVID-19 pandemic, the interdisciplinary collaborative spaces needed to enable teachers to successfully cross the boundaries between fields to envision and plan STEAM activities that truly integrate the arts into the technical fields of engineering and computer science. The evaluation results suggest that while the virtual format presented challenges, teachers found the summer institute beneficial and that the instrument design challenge successfully accomplished our primary objectives, to build community and model the use of technological tools. This suggests that the new format, with the reduced load from 120 to 60 hours, might be adequate to achieve our community building goals. However, teachers stated that they missed the substantial collaborative planning time that the Year 1 face-to-face schedule afforded. Moving forward, a compromise solution between the two models might be optimal.

Along with the challenges and constraints of implementing a professional development program in a virtual format, there were also some benefits. The digital environment allowed us to access a more diverse group of guest speakers from geographically distant locations, which would not have been possible to do in the face-to-face format. It also provided participants with more flexibility to balance professional learning, work commitments and home obligations, as they did not have to commute to attend the sessions and could join from any location. The virtual environment also allowed us to model different online platforms and digital tools that teachers could then use to augment their own instruction. The evaluation data suggests that virtual environments can build interdisciplinary, collaborative communities when intentional efforts to that end are clearly defined and implemented throughout. Going forward, GoSTEAM will capitalize on the lessons learned from the COVID-19 experience, 
developing a hybrid model for professional development that provides teachers with flexibility and access to remote people and technical tools, but that also creates opportunities for face-to-face collaboration and community building.

\section{AUTHOR INFORMATION Corresponding Author}

Analía E. Rao, MSW, LCSW. Research Associate II. Center for Education Integrating Science, Mathematics, and Computing (CEISMC), Georgia Institute of Technology. 505 10th St. NW, Atlanta, GA 30332. analia.rao@ceismc. gatech.edu

\section{Author Contributions}

The manuscript was written through contributions of all authors. All authors have given approval to the final version of the manuscript.

\section{ACKNOWLEDGMENTS}

The authors would like to thank the GoSTEAM program staff for their commitment and tireless work during an extremely challenging year. The authors gratefully acknowledge Georgia Tech faculty, student volunteers, and community organizations for their invaluable partnership. The authors would also like to acknowledge the hard labor and dedication of the teacher participants.

\section{FUNDING SOURCES}

This work would not have been possible without the financial support of The Goizueta Foundation.

\section{ABBREVIATIONS}

PBL: Project-Based Learning; STEAM: Science, Technology, Engineering, Art and Mathematics; STEM: Science, Technology, Engineering, and Mathematics; SWOT: Strengths, Weaknesses, Opportunities, and Threats

\section{REFERENCES}

Boice, K. L., Jackson, J. R., Alemdar, M., Rao, A. E., Grossman, S., and Usselman, M. C. (2021). Supporting teachers on their STEAM journey: A collaborative STEAM teacher training program. Education Sciences, 11(3), 105.

Darling-Hammond, L., Hyler, M. E., and Gardner, M. (2017). Effective teacher professional development. Learning Policy Institute.

Huser, Joyce et al. (2020). STEAM and the Role of the Arts in STEM. New York: State Education Agency Directors of Arts Education.
Kelton, M. L., and Saraniero, P. (2018). STEAM-y partnerships: A case of interdisciplinary professional development and collaboration. Journal of Museum Education, 43(1), 5565 .

Land, M. H. (2013). Full STEAM ahead: The benefits of integrating the arts into STEM. Procedia Computer Science, 20, 547-552.

Quigley, C. F., and Herro, D. (2016). "Finding the joy in the unknown": Implementation of STEAM teaching practices in middle school science and math classrooms. Journal of Science Education and Technology, 25(3), 410-426.

Herro, D., and Quigley, C. (2017). Exploring teachers' perceptions of STEAM teaching through professional development: implications for teacher educators. Professional Development in Education, 43(3), 416-438.

Silverstein, L. B., and Layne, S. (2010). What is arts integration. Washington, DC: The Kennedy Center for the Performing Arts. 